\title{
O debate acerca do caráter econômico da colonização na América e suas implicações políticas
}

\author{
Isadora Bueno Silva ${ }^{1}$
}

\begin{abstract}
RESUMO
Este artigo delineia diferentes percepções acerca do caráter econômico da colonização da América e das sociedades que dela emergem. Os debates sociológicos e, principalmente, historiográficos sobre o tema, se configuram como principal objeto. Os autores tratados foram definidos de maneira favorável para cumprir o objetivo, incorporando além de profissionais das Ciências Humanas; marxistas e militantes, visto que o passado é sempre significado no presente e esses lugares sociais são essenciais para compreender a História e suas relações presente-passado. Assim, os pensadores foram elencados para apreender a relação de interpretação dada no presente vivido por esses homens ao passado e suas supostas implicações políticas.

Palavras-chave: Colonização, América, Feudal, Capitalista, Marxista.
\end{abstract}

\begin{abstract}
This article approaches different perceptions about the economic character of the colonization of America and the societies that emerge from it. The sociological and, mainly, historiographical debates on the subject, are configured as main object. The treated authors were defined in a favorable way to fulfill the objective, incorporating besides Human Sciences professionals; Marxists and militants, so that the past is always signified in the present and these social places are essential to understand history and its present-past relations. Therefore, thinkers were listed to apprehend the relation of interpretation given in the present lived by these men to the past and their supposed political implications.
\end{abstract}

Keywords: Colonization, America, Capitalist, Feudal, Marxist.

\section{Introdução}

$\mathrm{Na}$ historiografia mundial e principalmente na latino-americana, o debate sobre o caráter da colonização das Américas é recorrente há muitos anos. Diversos pensadores, entre eles historiadores, buscam argumentar sobre a natureza feudal, capitalista ou nenhuma das opções mais difundidas

\footnotetext{
${ }^{1}$ Discente do Instituto de História. Email: isadora.bueno@outlook.com
} 
da colonização. Essa discussão, além de importante para a investigação do período colonial dentro da academia, tem implicações diretamente políticas. Tendo isso em vista, objetiva-se nesse artigo estudar e comparar as diferentes teses dos autores escolhidos sobre as premissas da colonização.

É importante compreender o que significam essas duas categorias capitalismo e feudalismo - para que possamos entender as posições de cada autor, seus êxitos e limites. Maurice Dobb (1977) afirma, sobre o modo de produção feudal, que:

[...]Fundamentalmente, o modo de produção no feudalismo foi o pequeno modo de produção - levado a cabo por pequenos produtores ligados à terra e aos seus instrumentos de produção. A relação social básica assentava-se sobre a extração do produto excedente deste pequeno modo de produção pela classe dominante feudal - uma relação de exploração alicerçada por vários métodos de "coação extra-econômica". (DOBB, 1977, p. 210)

Rodney Hilton (1977), ao apresentar o que "representa a palavra capitalismo", a define para diferentes autores. Ele aponta que Lipson concorda com a definição de Marx:

[...] no sentido de que sua característica essencial é a divisão de classes entre assalariados sem propriedade e empresários que possuem capital, em contraste com a organização característica medieval da indústria e da agricultura com base no pequeno produtor que possuía seus próprios meios de produção. (HILTON, 1977, p. 183)

Mas, para além de mobilizar conceitos, devemos nos atentar para a complexidade da passagem de um sistema para o outro, que guarda diversas opiniões até os dias atuais. Essa problemática está diretamente relacionada à definição do caráter da colonização da América, visto que, dependendo da concepção do autor acerca desse processo, o mesmo defende que a colonização foi capitalista ou feudal. No livro A transição do Feudalismo para o Capitalismo (1977), este debate se aprofunda, com a perspectiva de diferentes autores, em maioria marxista, sobre os processos efetivados 
durante esse transcurso, que de acordo com Eric Hobsbawn (1977), foi longo e "nada tem de uniforme".

Nesse movimento, nos interessa perceber a América. De que maneira a chegada ao continente e a colonização se integram na transição do feudalismo para o capitalismo, ou como defendem alguns autores, em um dos dois sistemas. Marx (2014), a insere como uma das causas de desenvolvimento do capitalismo nascente, que ainda não era uma realidade concretizada:

A descoberta da América, a circunavegação da África abriram um novo campo de ação à burguesia nascente. Os mercados das Índias Orientais e da China, a colonização da América, o intercâmbio com as colônias, o aumento dos meios de troca e das mercadorias em geral deram ao comércio, à navegação, à indústria, um impulso jamais conhecido antes e, em consequência, favoreceram o rápido desenvolvimento do elemento revolucionário na sociedade feudal em decomposição. (MARX, 2014, p. 40 e 41).

A História não tem significado por si mesma, nós damos interpretações posteriores aos acontecimentos. Por isso é lógico que, enquanto homens e mulheres pertencentes a certo contexto histórico e social, é improvável e, mais do que isso, eu diria impossível, conceber qualquer tipo de neutralidade. Como defende Jean Chesneaux (1994):

Se o passado conta, é pelo que significa para nós. Ele é produto de nossa memória coletiva, é o seu tecido fundamental. (...) esse passado, próximo ou longínquo, tem sempre um sentido para nós. Ele nos ajuda a compreender melhor a sociedade na qual vivemos hoje, a saber o que defender e preservar, saber também o que mudar e destruir. A história tem uma relação ativa com o passado. O passado está presente em todas as esferas da vida social. (CHESNEAUX, 1994, p. 22).

Portanto, acredito que seja importante destacar que as teses aqui apresentadas são formuladas por pessoas ativas histórica e politicamente, então é importante que nos atentemos a essa ambiência, de forma a problematizar esses lugares sociais que influenciam, inegavelmente, a significação do passado. 


\section{Um breve balanço sobre as discussões historiográficas e sociológicas pela perspectiva de Waldo Ansaldi}

Waldo Ansaldi (2014), no trabalho Notas para pensar las ciencias sociales latinoamericanas faz um balanço de algumas questões da área e os principais posicionamentos, perpassando, também, pela Historiografia. O autor trata do caráter da colonização como discussão essencial para entender as Ciências Sociais atualmente. Ele ressalta a defesa inicial de Sérgio Bagú (1949) do caráter capitalista, que abriria espaço para um movimento crítico dessa opinião, especialmente marxista, nas décadas de 60 e 70, o qual abordaremos alguns autores, como Caio Prado Jr.

Ansaldi atenta à necessidade posterior de superar os "dualismos", originando, por exemplo, a tese do colonialismo interno, que de acordo com ele, não teve muitos precursores. Na década de 60 ainda, como ele nos mostra, surge a teoria da dependência, defendida, como veremos no atual trabalho, por cientistas sociais como Fernando Henrique Cardoso. Essa teoria teria sido superada no período que o autor chama de "crise dos paradigmas", principalmente a marxista, quando, segundo ele, a tese se mostra insuficiente para apreender as mudanças ocorridas no interior do capitalismo.

Assim como defende Marc Bloch (2002), quando diz que a "História é filha de seu tempo", Waldo Ansaldi demonstra essa percepção para a Sociologia. Ele defende que com a "derrota" dos movimentos revolucionários das décadas de 60 e 70, o objetivo dos debates acadêmicos, acompanhando a política, passa da revolução socialista para a conquista efetiva da democracia. Essa passagem ocasiona, para o historiador, o abandono das teorias críticas e, em seu lugar, a incorporação dos debates externos, que, tanto na Historiografia como nas Ciências Sociais, seriam realçados os debates micro, sem apelo à superestrutura, que perdem, pouco a pouco, a noção de relações entre sujeitos e estrutura e, consequentemente, os debates 
econômicos e sociais, como o do caráter da colonização da América Latina (que passa a ser vista de maneira heterogênea e apenas as particularidades, nesse contexto, são levadas em consideração):

Desaparecieron las clases sociales, el cambio social, el desarrollo económico-social, las razones estructurales, cuestiones reemplazadas por sistemas electorales, partidos e instituciones políticas... Notable expansión disciplinaria, com correlativa fragmentación temática, igualmente notables en el caso de la Historiografía. En una y otra, ausencia de enfoques y explicaciones de carácter estructural, de análisis a escala de un país (mucho menos, como dije antes, de América Latina como um todo) y, a fortiori, de interacción entre sujetos y estructuras. (ANSALDI, 2014, p. 37).

Ansaldi nos auxilia a captar o movimento dos debates historiográficos e sociológicos do tema tratado e, sobretudo, a diversidade de posicionamentos apresentados que, mais do que apenas posições acadêmicas, de certa linha de pesquisa, guardam valores ideológicos e políticos da vivência de cada autor, como o lugar social de Waldo Ansaldi explicita: além de ser um historiador que analisa os processos históricos e sociológicos da América Latina, se alinha ideologicamente com o marxismo.

\section{A Teoria da Dependência e os pensadores marxistas}

A importância desse lugar social se evidencia, igualmente, na obra de Caio Prado Jr., historiador marxista da década de 60 que encara o caráter da colonização de maneira conexa à sua posição política. Fábio de Oliveira Maldonado (2016), graduado em Relações Internacionais e mestre no Programa de Pós-Graduação em Integração da América Latina, da Universidade de São Paulo (PROLAM-USP), também marxista e pesquisador nas áreas relativas ao tema, ressalta a defesa do historiador e seus adeptos da condição capitalista do processo de colonização.

O internacionalista cita autores favoráveis à tese do sentido capitalista como André Gunder Frank, Ruy Mauro Marini, Theotônio dos Santos e Vânia Bambirra, que, ao descartar a tese feudal, se alinham à ideia 
do capitalismo dependente. Essa percepção se relaciona evidentemente à política, visto que:

O entendimento de que o modo de produção brasileiro e latino-americano era feudal, apontava para a necessidade de sua superação mediante uma revolução democrático-burguesa, isto é, cumpriria a etapa clássica: feudalismo-capitalismo para que depois se chegasse ao socialismo. Neste sentido, rejeitadas tais teses, o entendimento do caráter revolucionário deveria per forza ser alterado. (MALDONADO, 2016, p.2).

Caio Prado Jr. (2014) descarta a tese de um modo de produção feudal na América Latina, externando conflito com os partidos comunistas da época, inclusive o Partido Comunista Brasileiro (PCB) no qual se inseria. A conviç̧ão desses partidos fortalecia o ideal de uma burguesia "progressista" que se uniria aos trabalhadores incitando a superação da "etapa" feudal para, só depois disso, ser possível a efetivação da Revolução.

Como Maldonado (2016) demonstra, outros pensadores latinoamericanos contemporâneos a Caio Prado discordavam dessa visão etapista. O historiador e esses intelectuais e militantes revolucionários denunciam a confirmação de uma burguesia conservadora e imperialista quando as ditaduras são implementadas na América Latina, de forma a conter um avanço social no continente, contrapondo o que defendiam os partidos comunistas. É interessante notar como o autor, ao negar a concepção antiimperialista de então, está preocupado justamente em que a esquerda passe de um conteúdo reformista/etapista para se tornar revolucionário. (MALDONADO, 2016, p. 9).

Dessa maneira, Caio Prado Jr. adere à Teoria da Dependência, que, como Ansaldi (2014) ressalta, incorpora diversos adeptos pela América Latina. Prado Jr. justifica que seu raciocínio se evidencia na realidade do país:

A situação de dependência e subordinação orgânica e funcional da economia brasileira com relação ao conjunto internacional de que participa é um fato que se prende às raízes da formação do país, como já temos repetidas vezes assinalado e é tão óbvio. Economia de exportação, 
constituída para o fim exclusivo de fornecer gêneros alimentares e matérias primas tropicais aos países e às populações das regiões temperadas da Europa, e mais tarde também da América, ela se organizará e funcionará em ligação íntima e estreita dependência do comércio internacional em função do qual se formou e se desenvolveu. Essa é a circunstância principal que tornará o Brasil tão vulnerável à penetração do capital financeiro internacional quando o capitalismo chega a essa fase de seu desenvolvimento. O país se fará imediata e como que automaticamente, sem resistência alguma, em fácil campo para suas operações. (PRADO JR. 2014, p. 116).

Fernando Henrique Cardoso e Enzo Faletto defendem, igualmente, a Teoria da Dependência. Para eles, um sistema econômico se configura quando: a acumulação e a expansão de capital não podem encontrar seu componente dinâmico essencial no interior do sistema (CARDOSO; FALETTO, 2008, p. 16). Durante o livro, os autores destacam essa dependência econômica como responsável pelas desigualdades nos países "periféricos" da América Latina, denunciando o equívoco do CEPAL ${ }^{2}$. É importante ressaltar que os sociólogos apontam como única saída para essas mazelas, a superação absoluta do capitalismo3:

Não é realista imaginar que o desenvolvimento capitalista resolverá problemas básicos para a maioria da população. Ao fim, o que deve ser discutido como alternativa não é a consolidação do Estado e a realização plena do "capitalismo autônomo", mas sim a sua superação. A questão relevante, então, é como construir caminhos para o socialismo. (CARDOSO; FALETTO, 2008, p. 19)

Ao justificar a metodologia empregada, a qual eles denominam a análise histórico-estrutural ${ }^{4}$ e a superação dos mecanicismos que se apoiam

\footnotetext{
2 A CEPAL é uma das cinco comissões regionais das Nações Unidas e sua sede está em Santiago do Chile. Foi fundada para contribuir ao desenvolvimento econômico da América Latina, coordenar as ações encaminhadas à sua promoção e reforçar as relações econômicas dos países entre si e com as outras nações do mundo. Posteriormente, seu trabalho foi ampliado aos países do Caribe e se incorporou o objetivo de promover o desenvolvimento social. (Comissão Econômica para a América Latina e o Caribe - CEPAL).

3 Apesar da trajetória incoerente de Fernando Henrique Cardoso, é importante pensar o que ele defendia nesse momento.

4 A precisão de uma interpretação histórico-estrutural deve ser testada pelo confronto entre o seu esboço das condições estruturais e tendências de transformação, e o processo sociopolítico efetivo. As realidades estão em jogo tanto na construção da interpretação como na sua validação prática: os dados não são incorporados à análise como se fossem estaticamente existentes; o importante é como eles mudam ao se desenvolver o processo social. (CARDOSO; FALETTO, 2008, p. 10).
} 
indistintamente na existência de um sistema capitalista para empreender certas teorias sem muito avançar, os autores objetivam delinear os processos para o alcance dessa condição nos países capitalistas, o que os leva à colonização e, evidentemente, à problemática do caráter econômico:

A tarefa importante é explicar como a direção econômica capitalista levou à criação de economias "capitalistas" escravas em diversos lugares da América Latina, à exploração de populações indígenas em outros lugares, e a uma economia baseada em assalariamento em alguns lugares, como em regiões do sul do continente. Em cada uma dessas situações, por trás das economias locais estava o capitalismo em sua forma mercantilista. Não eram sociedades "feudais". Mas não basta explicar as diferenças concretas entre, por exemplo, as plantations escravistas brasileiras e a economia argentina no século XIX. Ambas eram economias "capitalistas", mas organizadas em torno de diferentes relações de produção: num caso, a escravidão; no outro, relações que se desenvolveram em formas de produção quase capitalistas.

Assim, Fernando Henrique Cardoso e Enzo Faletto legitimam o caráter capitalista da colonização, mesmo que ainda na lógica mercantil. Eles salientam a heterogeneidade desse sentido capitalista, já que em cada país as relações de trabalho ocorreram de uma forma e consequentemente, o desenvolvimento do sistema nascente também, mas, sobretudo, a existência dessa essência na América Latina durante o período colonial é o que interessa, nesse momento de contextualização, aos autores.

\section{A interpretação de militantes revolucionários}

Nahuel Moreno (1977) critica alguns pensadores que se colocam como marxistas, mas que não utilizam de fato uma metodologia marxista. Esses autores, para ele, apenas concebem a existência de classes, a importância do fator econômico e alguns apontam a necessidade de uma revolução, como os sociólogos anteriormente mencionados. Eles supostamente seriam "positivistas-marxistas" ou "neoliberais marxistas", superando 
minimamente o positivismo formal da academia, porém, mantendo esse método aprendido nas universidades da época.

Convém lembrar que Moreno não é ligado à academia de maneira alguma, diferentemente dos pensadores aqui referidos até então, que são historiadores e sociólogos. Nahuel Moreno foi um militante revolucionário trotskista e seus textos são unicamente exposições de seus posicionamentos e orientações para a militância política, apesar de recorrentemente abordarem questões debatidas na Historiografia e Sociologia, já que, como defende Chesneaux (1994), o presente é quem questiona e significa o passado e a História.

Do mesmo modo, Luis Vitale, historiador argentino despendeu grande parte da sua vida à militância política, obteve nacionalidade chilena onde militava no sindicato e num partido revolucionário trotskista. A produção bibliográfica do historiador se constitui, majoritariamente, à explicação de processos históricos acerca de revoluções ou implicações para a possibilidade da efetivação do socialismo.

Entendo que, por se tratar do posicionamento de dois militantes trotskistas, que defendem assim como Caio Prado Jr. e outros intelectuais que o caráter da colonização das Américas influi diretamente na consolidação do socialismo, é essencial enunciar o conceito de Revolução Permanente, forjado por Marx e Engels e adotado e hoje diretamente vinculado por León Trotsky, para entender qual é a revolução que concebem esses autores.

Trotsky (1929) na obra $A$ revolução permanente reforça as diferentes concepções de como seria a passagem para o socialismo ${ }^{5}$, mas enfatiza que todas concordavam com a distinção entre a democracia e o socialismo, como "etapas", além de díspares, distantes da "evolução" social, denunciando uma perspectiva evolucionista. Tendo isso em vista, a teoria da revolução

\footnotetext{
5 [...] no que concerne à passagem ao socialismo, nem todos a concebiam de modo idêntico: os reformistas confessos a encaravam sob aspecto de reformas que dariam a democracia um conteúdo socialista (Jaurès); os revolucionários formais -reconheciam o caráter inelutável da violência revolucionária no momento da passagem ao socialismo (Guesde). (TROTSKY, 1929, p. 4).
} 
permanente se diferenciava pela percepção da indissolubilidade entre ambas: a democracia aconteceria juntamente com o socialismo nos países que ainda não haviam a alcançado.

Apesar de não ser o foco de Trotsky, essa formulação colide com o pensamento da necessidade idealizada pelos pensadores que capitulavam à tese da colonização feudal na América Latina da implementação da democracia burguesa, para haver, posteriormente, a superação da mesma nos países que foram colonizados, como defende Mariátegui, o qual Moreno crítica como um dos marxistas que não se disvencilhou da metodologia positivista. Contudo, a mais popular questão, que para o militante russo se coloca igualmente essencial, é a tese da indispensabilidade do internacionalismo:

[...] a teoria da revolução permanente implica o caráter internacional da revolução socialista que resulta do estado da economia e da estrutura social da humanidade. $\mathrm{O}$ internacionalismo não é um princípio abstrato: ele não é senão o reflexo político e teórico do caráter mundial da economia, do desenvolvimento mundial das forças produtivas e do ímpeto mundial da luta de classes. A revolução socialista começa no âmbito nacional, mas nele não pode permanecer. A revolução pro1etária não pode ser mantida em limites nacionais senão sob a forma de um regime transitório, mesmo que este dure muito tempo, como o demonstra o exemplo da União Soviética. No caso de existir uma ditadura proletária isolada, as contradições internas e externas aumentam inevitavelmente e ao mesmo passo que os êxitos. Se o Estado proletário continuar isolado, ele, ao cabo, sucumbirá vítima dessas contradições. Sua salvação reside unicamente na vitória do proletariado dos países avançados. Deste ponto de vista, a revolução nacional não constitui um fim em si, apenas representa um elo da cadeia internacional. A revolução internacional, a despeito de seus recuos e refluxos provisórios, representa um processo permanente. (TROTSKY, 1929, p. 5).

Portanto, os militantes trotskistas defendem prioritariamente uma revolução socialista da classe trabalhadora e internacionalista. Esse posicionamento, nitidamente, influencia a visão dos autores sobre a colonização e as teorias formuladas a partir da mesma. Essa importância se evidencia quando Moreno (1977) critica a abertura para a inserção da burguesia no processo revolucionário defendida por alguns marxistas 
embasados no caráter feudal da colonização. $O$ argentino discorda da conciliação de classes e, sobretudo, da própria essência feudal do processo de colonização:

La colonización española, portuguesa, inglesa, francesa y holandesa en América, fue esencialmente capitalista. Sus objetivos fueron capitalistas y no feudales: organizar la producción y los descubrimientos para efectuar ganancias prodigiosas y para colocar mercancías en el mercado mundial. No inauguraron un sistema de producción capitalista porque no había en América un ejército de trabajadores libres en el mercado. Es así como los colonizadores, para poder explotar en forma capitalista a América, se ven obligados a recurrir a relaciones de producción no capitalistas: la esclavitud o una semiesclavitud de los indígenas. Producción y descubrimiento por objetos capitalistas; relaciones esclavas o semiesclavas; formas y terminologías feudales (al igual que el capitalismo mediterráneo), son los tres pilares en que se asentó la colonización de América. (MORENO, 1977).

Vitale (1999), por sua vez, elucida que o caráter feudal é externo, o que gerou liberais e reformistas defensores dessa tese, pela concessão de títulos de nobreza, por exemplo, que, ele ressalta, eram $\operatorname{comprados}^{6} \operatorname{com}_{0}$ dinheiro adquirido com atividades burguesas. Outra confirmação do equívoco desses pensadores, de acordo com ele, é a existência de novas classes sociais e a importância da pequeno-burguesa para compreender esses fenômenos, pormenorizada por alguns historiadores, já que: “(...) a estruturação de uma classe média não é própria do feudalismo." (VITALE, 1966 apud LÖWY, 1999, p. 446).

Ele defende, dessa forma, que: "a economia colonial gerou uma burguesia de matérias-primas" (VITALE, 1966 apud LÖWY, 1999, p. 446). Desmontando a necessidade de passagem de etapas, embasada no ciclo europeu, visto que a burguesia, nas Américas, surge ainda na Colônia. Mas, para ele, sem a "roupagem" moderna, dada sua condição dependente e abastecedora da metrópole exclusivamente, com a ressalva, por esse motivo, de não ser uma burguesia industrial mais facilmente deduzida dentro da

\footnotetext{
${ }^{6}$ Grifo nosso, 2018.
} 
lógica capitalista. Assim, ele refuta a intenção de uma revolução etapista e a união com a burguesia "progressista":

\begin{abstract}
Sintetizando, é falso que a aristocracia feudal governou os países latinoamericanos. O certo é que o poder foi exercido por uma burguesia exportadora de matéria-prima, que condicionou o atraso do nosso continente. A etapa imperialista significou a transferência destas matérias-primas para o capital financeiro estrangeiro. A burguesia industrial de dentes-de-leite manteve-se independente do imperialismo por sua incapacidade histórica de desenvolver a indústria pesada, condição básica para a evolução progressiva de um país na atual etapa da civilização. $\mathrm{O}$ atraso da América Latina não é produto do feudalismo, mas de uma burguesia que esgotou todas as possibilidades de desenvolvimento de um continente semicolonial em plena época imperialista. Assim, é falso afirmar, como faz o revisionismo, que falta uma etapa de desenvolvimento capitalista, que pode ser realizada pela "burguesia progressista". (VITALE, 1966 apud LÖWY, 1999, p. 449).
\end{abstract}

A Revolução que ele defende, tendo em vista a negação do reformismo e o seu alinhamento político e teórico com o trotskismo, implica em:

A nova geração latino-americana, surgida sob o estímulo da Revolução Cubana, não poderá mais ser mistificada com os velhos esquemas da revolução por etapas, chamada de democrática, antifeudal, agrária, nacional ou anti-imperialista. Sabe que há apenas um caminho para derrotar os inimigos seculares do atraso continental: a insurreição popular armada para implantar o socialismo. (VITALE, 1966 apud LÖWY, 1999, p. 452).

\title{
5 Uma percepção distinta
}

Ciro Flamarion Cardoso e Héctor Pérez Brignoli (1983) declaram os principais problemas teóricos antes mesmo de iniciarem o debate estabelecido sobre as bases da economia colonial. Eles denunciam Wallerstein como adepto de um dos equívocos apontados, desse modo, fica nítida a discordância dos autores com as abordagens teóricas colocadas aqui anteriormente. O "dilema" dos pesquisadores interessados nas sociedades americanas no período colonial que eles apresentam se constitui da seguinte maneira: 
Por um lado, tais sociedades só adquirem pleno sentido se são abordadas como parte de um conjunto mais vasto, posto que surgem como anexos complementares da economia europeia, e sob a dependência de núcleos metropolitanos que é preciso considerar para compreender a racionalidade da economia colonial. Por outro, a empresa colonial fez aparecer sociedades com estruturas internas que possuem uma lógica que não se reduz à sua vinculação externa com o comércio atlântico e com as suas respectivas metrópoles políticas: desta forma, defini-las como anexo ou parte integrante de um conjunto mais vasto é um momento central da análise, mas não o bastante. É necessário também abordar as próprias estruturas internas, descobrir suas especificidades e seu funcionamento. (CARDOSO; BRIGNOLI, 1983, p. 63).

Os autores são extremamente coerentes com a perspectiva defendida, tendo em vista que definem e, posteriormente, exploram diferentes tipologias para classificar essas sociedades (as principais se constituem, de acordo com eles, por: segundo as potências colonizadoras; segundo o grau de vinculação ao mercado mundial; segundos os tipos de produção e segundo a mão de obra e do caráter da colonização). Não será possível que nos estendamos nessas categorias e nos aprofundamentos concebidos por eles, por extrapolar o objetivo do artigo, basta, nesse momento, que entendamos que esse método é adotado pelo discernimento que têm os historiadores de considerar a economia mundial e concomitantemente, a realidade das colônias americanas:

[...] é evidente que, em nossa opinião, a colonização da América na época do mercantilismo somente poderia engendrar sociedades coloniais précapitalistas. Estas sociedades, porém, não eram todas do mesmo tipo. (CARDOSO; BRIGNOLI, 1983, p. 75).

A produção historiográfica de Ciro Flamarion Cardoso é em grande parte preenchida pelos estudos de Antiguidade e, sobretudo, de Egiptologia, mas o início de sua carreira é associado comumente a um marxismo mais "fechado" que foi sendo desenvolvido no decorrer de sua carreira acadêmica especialmente nas obras conjuntas com Héctor Brignoli, que, por sua vez, se volta mais aos estudos econômicos e sobre a América Latina. Os historiadores, ao expandirem nos estudos marxistas, contribuem 
notadamente para o estabelecimento do conceito de "Modo de Produção Escravista Colonial".

\section{Considerações Finais}

Este trabalho representa uma limitada contribuição para os debates tratados, levando em consideração que compreende autores previamente escolhidos de acordo com recortes específicos. É essencial ressaltar que os pensadores, em suma maioria, se localizam temporalmente mais recuados e que é necessário que continuemos pesquisando, de maneira a incorporar novas percepções, descobertas e conflitos da Historiografia atual a esses debates existentes que ainda não foram superados e inovar as questões que se inserem no mundo acadêmico como ultrapassadas ou solucionadas.

Além disso, é importante que percebamos as diversas relações do período, como defendem os últimos autores, e, sobretudo, dos sujeitos sociais presentes nessas realidades estudadas, sem abrir mão dos conceitos marxistas ainda válidos e significativos para compreender os debates existentes e a própria História, que se constitui de forma dialética e por sujeitos ativos, em constante relação com a superestrutura, afinal, até então, a História do Mundo é a história da luta de classes.

\section{Referências bibliográficas}

ANSALDI, Waldo. Entre perpejidades y angustias: notas para pensar las ciencias sociales latino-americanas. Revista de Estudos e Pesquisas sobre as Américas, v.8, n.2, 2014.

BLOCH, Marc. Apologia da História ou o Ofício do Historiador. São Paulo: Zahar, 2002. 
CARDOSO, Ciro Flamarion; BRIGNOLI, Héctor Perez. História Econômica da América Latina: Sistemas agrários e história colonial Economias de exportação e desenvolvimento capitalista. Rio de Janeiro: Edições Graal, 1983.

CARDOSO, Fernando Henrique, and FALETTO, Enzo. Repensando dependência e desenvolvimento na América Latina. In SORJ, B., CARDOSO, FH., and FONT, M., orgs. Economia e movimentos sociais na América Latina [online]. Rio de Janeiro: Centro Edelstein de Pesquisa Social, 2008. pp. 4-20. ISBN 978-85- 99662-59-5. Available from SciELO Books.

CHESNEAUX, Jean. Devemos fazer tábula rasa do passado?. São Paulo: Ática, 1994.

Comissão Econômica para a América Latina. Sobre a CEPAL. Disponível em: https://www.cepal.org/pt-br/about. Acesso em: 12/06/2018.

ENGELS, F; MARX, K. O Manifesto Comunista. Petrópolis, RJ: Vozes, 2014, $2^{\text {a }}$ ed.

JÚNIOR, C P. História econômica do Brasil. São Paulo: Editora Brasiliense, 31 ed., 1976.

JUNIOR, C. P. A revolução brasileira - A questão agrária no Brasil. São Paulo: Companhia das Letras, 2014.

LÖWY, Michael. O marxismo na América Latina: Uma antologia de 1909 aos dias atuais. Tradução de Cláuudia Schiling e Luís Carlos Borges. São Paulo: Editora Fundação Perseu Abramo, 1999.

MALDONADO, F. A influência do pensamento de Caio Prado Jr na obra de Ruy Mauro Marini. Anais do II Simpósio Internacional Pensar e Repensar a América Latina, 2016.

MORENO, Nahuel. Cuatro tesis sobre la colonización española y portuguesa en América. Edición electrónica Diciembre 2001. (Tomado del Apéndice del Libro "Para comprender la Historia", del filosofo norteamericano George Novack, publicado por Editorial Pluma, Colombia, 1977). 
Silva

O debate acerca do caráter econômico da colonização ...

NOVACK, George. Para compreender la Historia. Ediciones Pluma, Buenos Aires, 1975.

SWEEZY, P e outros. A transição do feudalismo para o capitalismo. Tradução de Isabel Didonnet. Rio de Janeiro: Paz e Terra, 1977.

TROTSKY, Leon. A revolução permanente. Prínkipo, 1929. Disponível em: https://www.marxists.org/portugues/trotsky/index.htm. Acesso em: 08/06/2018. 